\title{
PERANAN SEKTOR PERTANIAN TERHADAP PEREKONOMIAN DI KOTA BITUNG
}

\author{
The Role Of The Agriculture Sector On The Economy In The City Of Bitung
}

\author{
Gustafito J.M. Wehantouw $^{(1)}$, Oktavianus Porajouw ${ }^{(2)}$,_Melissa L.G.Taroreh ${ }^{(2)}$
}

1) Mahasiswa Program Studi Sosial Ekonomi Pertanian, Fakultas Pertanian, Universitas Sam Ratulangi, Manado

2) Dosen Program Studi Sosial Ekonomi Pertanian, Fakultas Pertanian, Universitas Sam Ratulangi, Manado *Penulis untuk korespondensi: fitostunter118@gmail.com

\begin{tabular}{ll}
\hline Naskah diterima melalui Email Jurnal Ilmiah agrisosioekonomi@unsrat.ac.id & : Senin, 15 Maret 2021 \\
Disetujui diterbitkan & : Jumat, 28 Mei 2021 \\
\hline
\end{tabular}

\begin{abstract}
The research aims to describe the role of the agricultural sector in the economy in Bitung City from 2010 to 2019. The study was conducted for 3 months from June 2020 to September 2020. The type of data used in this study is secondary data obtained from the Central Statistics Agency (BPS) of Bitung City, namely in the form of GRDP of Bitung City and North Sulawesi Province for the period 2010 to 2019. Supporting data is in the form of other secondary data relevant to this study. The data collected were analyzed descriptively and presented in tabular form. The results showed that the contribution of the agricultural sector to the GRDP of Bitung City in 2019 was 16.6 percent, although it has decreased since 2010 by 17.8 percent, but the agricultural sector still ranks second after the manufacturing sector with a contribution of 32.84 percent in in 2019. The growth of the agricultural sector, although fluctuating, tends to increase from 6.33 percent in 2012 to 9.06 percent in 2019. The LQ value of the agricultural sector, even though it was less than one in 2019, was 0.85, but continues to increase compared to last year. 2010 amounted to 0.75, and the agricultural sector, especially the capture or fishing fisheries subsector, is the exporting sector to other districts / cities in North Sulawesi Province. Based on the results of this study, it can be concluded that the agricultural sector has an important role in the economy of Bitung City, because this sector is not only an exporting sector, especially the capture fisheries sub-sector, but also as a provider of raw materials for the processing industry in Bitung City.
\end{abstract}

Keyword: roles; agriculture sector; economy

\begin{abstract}
ABSTRAK
Penelitian ini bertujuan untuk mendeskripsikan peranan sektor pertanian terhadap perekonomian di Kota Bitung tahun 2010 sampai 2019. Penelitian dilakukan selama 3 bulam mulai dari bulan Juni 2020 sampai September 2020. Jenis data yang digunakan dalam penelitian ini ialah data sekunder yang diperoleh dari Badan Pusat Statistik (BPS) Kota Bitung, yaitu data PDRB Kota Bitung dan PDRB Provinsi Sulawesi Utara periode tahun 2010 sampai 2019. Data pendukung berupa data sekunder lain yang relevan dengan penelitian ini yaitu hasil-hasil penelitian terkait. Data yang diperoleh dianalisis secara deskriptif dan disajikan dalam bentuk tabel. Hasil penelitian menunjukkan bahwa kontribusi sektor pertanian terhadap PDRB Kota Bitung pada 2019 sebesar 16,6 persen, walaupun mengalami penurunan sejak tahun 2010 sebesar 17,8 persen, tetapi kontribusi sektor pertanian tetap menempati urutan kedua sesudah sektor industri pengolahan pada urutan pertama dengan kontribusi sebesar 32,84 persen pada tahun 2019. Pertumbuhan sektor pertanian, walaupun berfluktuasi, tetapi cenderung meningkat dari 6,33 persen tahun 2012 menjadi 9,06 persen tahun 2019. Nilai LQ sektor pertanian walaupun lebih kecil satu pada tahun 2019 yakni sebesar 0,85 tetapi terus meningkat dibandingkan tahun 2010 sebesar 0,75, dan sektor pertanian terutama subsektor perikanan tangkap merupakan sektor pengekspor ke kabupaten/kota lainnya di Provinsi Sulawesi Utara. Berdasarkan hasil penelitian tersebut, dapat ditarik kesimpulan bahwa sektor pertanian memiliki peran penting terhadap perekonomian Kota Bitung, karena sektor ini selain sebagai sektor pengekspor, terutama sub-sektor perikanan tangkap, juga sebagai sektor penyedia bahan baku industri pengolahan di Kota Bitung.
\end{abstract}

Keyword: peranan; sektor pertanian; ekonomi 


\section{PENDAHULUAN}

Pembangunan ekonomi daerah adalah suatu proses saat pemerintah daerah dan masyarakat mengelolah setiap sumber daya yang ada dan selanjutnya membentuk suatu pola kemitraan antara pemerintah daerah dengan sector swasta untuk menciptakan satu lapangan kerja baru dan dapat merangsang perkembangan kegiatan ekonomi (pertumbuhan ekonomi) dalam wilayah tersebut (Arsyad, 1999). Sasaran akhir dari kebijakan pembangunan tersebut adalah untuk dapat mendorong dan meningkatkan pertumbuhan ekonomi dan kesejahteraan sosial secara menyeluruh sesuai dengan keinginan dan aspirasi yang berkembang (Syafrizal, 2008).

Sektor pertanian di Indonesia merupakan tulang punggung dari perekonomian dan pembangunan nasional, hal tersebut dapat dilihat dalam pembentukan Produk Domestik Bruto (PDB), penerimaan devisa, penyerapan tenaga kerja, penyediaan pangan, dan penyediaan bahan baku industry. Sektor pertanian juga berperan dalam memeratakan pembangunan melalui upaya pengentasan kemiskinan dan perbaikan pendapatan masyarakat. Selain itu, sektor pertanian juga telah menjadi salah satu pembentuk budaya bangsa dan penyeimbang ekosistem. Sektor pertanian merupakan sektor yang mendapatkan perhatian cukup besar dari pemerintah dikarenakan perannya yang sangat penting dalam rangka pembangunan ekonomi jangka panjang maupun dalam rangka pemulihan ekonomi bangsa (Antara, 2009).

Kota Bitung adalah salah satu kota di Provinsi Sulawesi Utara. Kota ini memiliki perkembangan yang cepat karena terdapat pelabuhan laut yang mendorong percepatan pembangunan. Sektor pertanian di Kota Bitung menjadi prioritas bagi pembangunan untuk kesejahteraan Kota Bitung. Itu di karenakan sektor pertanian masih memiliki peluang yang sangat besar untuk dikembangkan di tengah masyarakat, khusunya petani. Kota Bitung juga dikenal sebagai kota maritim, karena itu sub sektor perikanan tangkap dijadikan sebagai sektor unggulan Kota Bitung, sebagai penyedia bahan baku pabrik pengalengan ikan di Kawasan Ekonomi Khusus Kota Bitung. Berdasarkan gambaran tersebut, maka diperlukan penelitian untuk menganalisis peranan sektor pertanian bagi perekonomi Kota Bitung selama sepuluh tahun terakhir (2010-2019)

\section{METODOLOGI PENELITIAN}

Penelitian ini dilaksanakan di Kota Bitung, Provinsi Sulawesi Utara, selama 3 bulan (Juni September 202). Penelitian ini menggunakan data sekunder yang diperoleh dari Badan Pusat Statistik (BPS) Kota Bitung, yaitu data Produk Domestik
Regional Bruto (PDRB) atas dasar harga konstan 2010, Kota Bitung dan Provinsi Sulawesi Utara periode 2010-2019 dalam rupiah. Berdasarkan PDRB tersebut, maka dapat diperoleh gambaran tentang peranan sektor pertanian terhadap perekonomian Kota Bitung, yang diukur dari besaran kontribusi sektor, tren pertumbuhan sektor, dan basis ekonomi/konsentrasi sektor. Rumus-rumus yang digunakan adalah sebagai berikut:

1) Analisis kontribusi sektor pertanian;

$$
\text { Kontribusi }=\frac{\text { PDRB Sektor Pertanian }}{\text { PDRB Total }}
$$

2) Analisis laju pertumbuhan PDRB sektor pertanian:

$$
\mathrm{G}=\frac{\mathrm{PDRB}_{1}-\mathrm{PDRB}_{0}}{\mathrm{PDRB}_{0}} x 100 \%
$$

Keterangan :

$\mathrm{G}=$ laju pertumbuhan ekonomi

$\mathrm{PDRB}_{1}=$ PDRB ADHK pada tahun sekarang

$\mathrm{PDRB}_{0}=\mathrm{PDRB} A D H K$ pada tahun dasar

3). Analisis basis ekonomi menggunakan Location Quotient (LQ). LQ dihitung dengan mengukur konsentrasi dari suatu kegiatan sektor ekomomi dalam suatu daerah dibandingkan dengan peranannya dalam perekonomian daerah tersebut dengan peran kegiatan sektor ekonomi sejenis dalam perekonomian regional atau nasional (Arsyad, 2010).

$$
\mathrm{LQ}=\frac{\mathrm{PDRB}_{\mathrm{PK}} / \mathrm{PDRB}_{\mathrm{TK}}}{\mathrm{PDRB}_{\mathrm{PP}} / \mathrm{PDRB}_{\mathrm{TP}}}
$$

Keterangan :

$\mathrm{PDRB}_{\mathrm{PK}}=$ jumlah $\mathrm{PDRB}$ sektor pertanian Kota Bitung

$\mathrm{PDRB}_{\mathrm{TK}}=$ jumlah PDRB seluruh sektor total Kota Bitung

$\mathrm{PDRB}_{\mathrm{P}}=$ jumlah PDRB sektor pertanian Povinsi Sulawesi Utara

$\mathrm{PDRB}_{\mathrm{TP}}=$ jumlah PDRB seluruh sektor total Provinsi Sulawesi Utara.

Kriteria basis/non-basis:

a. Apabila LQ > 1, sektor tersebut merupakan sektor basis, artinya sebagai sektor pengekspor / memiliki peranan sangat penting bagi perekonomian.

b. Apabila $L Q=1$, maka sektor tersebut merupakan sektor non basis, sektor tersebut hanya untuk memenuhi kebutuhan daerahnya sendiri/kurang berperan.

c. Apabila LQ <1, maka sektor tersebut merupakan sektor non basis, sektor tersebut tidak potensial untuk dikembangkan. 


\section{HASIL DAN PEMBAHASAN}

Deskripsi Daerah Penelitian

Kota Bitung merupakan salah satu kota besar yang terletak di Timur Laut Pulau Sulawesi Utara, dengan jarak tempuh ke ibu kota $40 \mathrm{Km}$, Kota Bitung dapat dicapai dengan menggunakan transportasdarat dan laut. Secara astronomis, Kota Bitung terletak antara $1^{\circ} 23^{\prime} 23^{\prime \prime}-1^{\circ} 35^{\prime} 39^{\prime \prime}$ LU dan $125^{\circ} 1^{\prime} 43^{\prime \prime}-125^{\circ} 18^{\prime} 13^{\prime \prime} \mathrm{BT}$.

Berdasarkan posisi geografisnya, Kota Bitung memiliki batas-batas:

Sebelah Utara berbatasan dengan Kecamatan Likupang (Kabupaten Minahasa Utara) dan Laut Maluku; Sebelah Selatan berbatasan dengan Laut Maluku; Sebelah Barat berbatasan Kecamatan Kauditan (Kabupaten Minahasa Utara); Sebelah Timur berbatasan dengan Laut Maluku.
Berdasarkan letak geografisnya, Kota Bitung terletak di daratan pulau Sulawesi dan sebagian adalah daerah kepulauan yaitu Pulau Lembeh. Kota Bitung terdiri dari 8 Kecamatan, 6 Kecamatan terletak di pulau Sulawesi yaitu Kecamatan Madidir, Matuari, Girian, Aertembaga, Maesa dan Ranowulu dan 2 Kecamatan terletak di Pulau Lembeh yaitu Lembeh Selatan dan Lembeh Utara.

\section{Kondisi Kependudukan}

Jumlah penduduk di Kota Bitung berdasarkan proyeksi penduduk pada tahun 2019 sebanyak 223.926 jiwa. Untuk lebih jelasnya data mengenai jumlah penduduk di Kota Bitung tiap kecamatan dapat dilihat pada Tabel 1, dimana daerah yang memiliki tingkat kepadatan paling tinggi adalah Kecamatan Maesa dan kecamatan yang memiliki kepadatan terendah adalah Kecamatan Ranowulu.

Tabel 1. Jumlah Penduduk Tiap Kecamatan Berdasarkan Jenis Kelamin dan Rasio Jenis Kelamin di Kota Bitung

\begin{tabular}{llrrrr}
\hline No & Kecamatan & Laki - Laki & Perempuan & \multicolumn{1}{l}{ Total } & \multicolumn{1}{l}{ Rasio } \\
\hline 1 & Madidir & $18,441.00$ & $18,128.00$ & $36,569.00$ & 101.73 \\
2 & Matuari & $19,164.00$ & $18,408.00$ & $37,572.00$ & 104.11 \\
3 & Girian & $18,846.00$ & $17,941.00$ & $36,787.00$ & 105.04 \\
4 & Lembeh Selatan & $5,853.00$ & $5,297.00$ & $11,150.00$ & 110.50 \\
5 & Lembeh Utara & $5,014.00$ & $4,833.00$ & $9,847.00$ & 103.75 \\
6 & Aertembaga & $15,915.00$ & $14,913.00$ & $30,828.00$ & 106.72 \\
7 & Maesa & $21,186.00$ & $19,968.00$ & $41,154.00$ & 106.10 \\
8 & Ranowulu & $10,324.00$ & $9,695.00$ & $20,019.00$ & 106.49 \\
\hline Jumlah & $114,743.00$ & $109,183.00$ & $223,926.00$ & 105.09 \\
\hline
\end{tabular}

Sumber : Diolah dari Data Sekunder, 2020

Perbandinga antara penduduk laki-laki dan perempuan di tiap-tiap kecamatan di Kota Bitung pada Tahun 2019. Kecamatan Maesa memiliki jumlah penduduk terbanyak di Kota Bitung, dan juga memiliki penduduk laki-laki dan penduduk perempuan paling besar dibandingkan dengan kecamatan-kecamatan lainnya.

\section{Bidang Pendidikan}

Salah satu komponen yang berkaitan langsung dengan peningkatan sumber daya manusia (SDM) adalah pendidikan. Oleh karena itu kualitas SDM selalu diupayakan untuk ditingkatkan melalui tingkat pendidikan yang berkualitas demi tercapainya keberhasilan pendidikan. Untuk mengukur proporsi anak yang bersekolah tepat pada waktunya dapat dilihat dengan indikator Angka Partisipan Murni (APM). APM menunjukan seberapa banyak penduduk usia sekolah yang sudah memanfaatkan fasilitas pendidikan sesuai dengan usia pada jenjang pendidikanya. APM Kota Bitung tahun 2019 untuk jenjang SD/MI, SMP/MTs, dan SMA/SMK/MA masing-masing sebesar 98,31; 75,02; 57,04.Angka Partisipasi Sekolah (APS) mengukur proporsi anak yang masih bersekolah pada suatu kelompok umur sekolah jenjang pendidikan tertentu. Angka ini menunjukkan gambaran secara umum tentang banyaknya anak kelompok umur tertentu yang sedang bersekolah tanpa memperhatikan jenjang pendidikan yang sedang diikuti.

\section{Kontribusi Sektor Pertanian Di Kota Bitung}

Sebagai salah satu penggerak perekonomian di Kota Bitung, sektor pertanian memiliki peran yang sangat penting. Oleh sebab itu, perlu dilihat seberapa besar kontribusi yang diberikan oleh sektor pertanian terhadap PDRB Kota Bitung dalam mendorong pertumbuhan perekonomian di Kota Bitung. Presentase kotnribusi sektor pertanian terhadap PDRB Kota Tomohon tahun 2010 sampai 2019 dapat dilihat pada Tabel 2. 
Tabel 2. Kontribusi Sektor Pertanian di Kota Bitung

\begin{tabular}{ccccc}
\hline No & Tahun & PDRB Pertanian & $\begin{array}{c}\text { TotalPDRB } \\
\text { Kota Bitung }\end{array}$ & $\begin{array}{c}\text { Kontribusi Sektor } \\
\text { Pertanian }(\%)\end{array}$ \\
\hline 1 & 2010 & $121,560,137$ & $684,576,964$ & 17.8 \\
2 & 2011 & $123,588,573$ & $724,781,607$ & 17.1 \\
3 & 2012 & $131,411,355$ & $771,540,010$ & 17.0 \\
4 & 2013 & $147,102,739$ & $822,915,225$ & 17.9 \\
5 & 2014 & $155,043,403$ & $875,530,469$ & 17.7 \\
6 & 2015 & $148,798,970$ & $906,484,235$ & 16.4 \\
7 & 2016 & $153,376,250$ & $953,754,485$ & 16.1 \\
8 & 2017 & $159,645,801$ & $1,012,735,310$ & 15.8 \\
9 & 2018 & $169,122,217$ & $1,073,583,424$ & 15.8 \\
10 & 2019 & $184,449,745$ & $1,118,560,052$ & 16.5 \\
\hline
\end{tabular}

Sumber : Diolah dari Data Sekunder, 2020

Tabel 2 menunjukkan kontribusi sektor pertanian terhadap PDRB Kota Bitung pada 2010 sampai 2019 rata-rata mengalami penurunan, kenaikan hanya terjadi pata tahun 2013 yaitu sebesar $17,9 \%$.

\section{Laju Pertumbuhan Sektor}

Pertumbuhan ekonomi secara umum diartikan sebagai suatu ukutan kuantitatifyang menggambarkan perkembangan suatu perekonomian dalam suatu tahuntertentu apabila dibandingkan dengan tahun sebelumnya. Perkembangan tersebutselalu dinyatakan dalam bentuk presentase perubahan pendapatan nasional padasuatu tahun tertentu dibandingkan dengan tahun sebelumnya (Sukirno, 2006), untuk melihat pertumbuhan sektor pertanian dapat dilihat pada Tabel 3.

Berdasarkan Tabel 3, pertumbuhan sektor pertanian dari tahun 2010 sampai 2019 cenderung meningkat, walupun sempat menurun pada tahun 2014, bahkan mengalami pertumbuhan negatif pada tahun 2015, tetapi meningkat kembali pada tahun 2016 hingga mencapai Sembilan persen tahun 2019.

Tabel 3. Pertumbuhan Sektor Pertanian Kota Bitung

\begin{tabular}{cccc}
\hline No & Tahun & PDRB Pertanian & Pertumbuhan (\%) \\
\hline 1 & 2010 & $121,560,137$ & - \\
2 & 2011 & $123,588,573$ & 1.67 \\
3 & 2012 & $131,411,355$ & 6.33 \\
4 & 2013 & $147,102,739$ & 11.94 \\
5 & 2014 & $155,043,403$ & 5.40 \\
6 & 2015 & $148,798,970$ & -4.03 \\
7 & 2016 & $153,376,250$ & 3.08 \\
8 & 2017 & $159,645,801$ & 4.09 \\
9 & 2018 & $169,122,217$ & 5.94 \\
10 & 2019 & $184,449,745$ & 9.06 \\
\hline
\end{tabular}

Sumber : Diolah dari Data Sekunder, 2020

\section{Menentukan Sektor Basis di Kota Bitung}

Sektor basis adalah sektor potensial yang dimiliki oleh setiap daerah dan menjadi keunggulan komparatif untuk terus menerus dikembangkan dengan berbagai upaya dari pemerintah yang bekerjasama dengan masyarakat. Berdasarkan hasil perhitungan LQ sektor-sektor ekonomi di Kota Bitung memberikan gambaran mana sektor basis dan sektor non-basis. seperti ditampilkan pada Tabel 4. Tabel 4 menunjukkan bahwa ada tiga sektor yang termasuk sektor basis, yaitu: sektor industri pengolahan; sektor pengadaan air, pengolahan sampah, limbah dan daur ulang; sektor transportasi dan pergudangan. 
Tabel 4. NILAI LQ TAHUN 2019

\begin{tabular}{|c|c|c|}
\hline LAPANGAN USAHA & LQ & Ket \\
\hline A. PERTANIAN, KEHUTANAN \& PERIKANAN & 0.85 & Non Basis \\
\hline B. PERTAMBANGAN DAN PENGGALIAN & 0.10 & Non Basis \\
\hline C. INDUSTRI PENGOLAHAN & 3.48 & Basis \\
\hline D. PENGADAAN LISTRIK DAN GAS & 0.93 & Non Basis \\
\hline E. PENGADAAN AIR, PENGOLAHAN SAMPAH, LIMBAH DAN DAUR ULANG & 1.49 & Basis \\
\hline F. KONSTRUKSI & 0.83 & Non Basis \\
\hline $\begin{array}{l}\text { G. PERDAGANGAN BSAR DAN ECERAN; REPARASI MOBIL DAN SEPEDA } \\
\text { MOTOR }\end{array}$ & 0.75 & Non Basis \\
\hline H. TRANSPORTASI DAN PERGUDANGAN & 1.59 & Basis \\
\hline I. PENYEDIAAN AKOMODASI DAN MAKAN MINUM & 0.39 & Non Basis \\
\hline J. INFORMASI DAN KOMUNIKASI & 0.45 & Non Basis \\
\hline K. JASA KEUANGAAN DAN ASURANSI & 0.89 & Non Basis \\
\hline L. REAL ESTATE & 0.66 & Non Basis \\
\hline M,N JASA PERUSAHAAN & 0.27 & Non Basis \\
\hline $\begin{array}{l}\text { O. ADMINISTRASI PEMERINTAHAN, PERTAHANAN DAN JAMINAN SOSIAL } \\
\text { WAJIB }\end{array}$ & 0.28 & Non Basis \\
\hline P. JASA PENDIDIKAN & 0.30 & Non Basis \\
\hline Q. JASA KESEHATAN DAN KEGIATAN SOSIAL & 0.57 & Non Basis \\
\hline R,S,T,U JASA LAINNYA & 0.43 & Non Basis \\
\hline
\end{tabular}

Sumber : Diolah dari Data Sekunder, 2020

Sektor pertanian ternyata bukan merupakan sektor basis, padahal sektor pertanian di Kota Bitung memiliki peran yang sangat penting karena Kota Bitung memiliki pelabuhan perikanan yang cukup besar, dan beberapa perusahaan/pabrik pengalengan ikan. Oleh karena itu, sub sektor perikanan tangkap ditetapkan sebagai sektor unggulan di Kota Bitung. Sub-sektor perikanan tangkap di Kota Bitung merupakan sektor pengekspor, karena perikanan tangkap selain menyediakan bahan baku ikan untuk pabrik pengalengan ikan di Kota Bitung, juga sebagai penyedia kebutuhan ikan untuk konsumsi masyarakat di Sulawesi Utara. Berdasarkan peran sub sektor perikanan tangkap tersebut, maka jika didasarkan metode arbriter sederhana yang mengasumsikan bahwa semua industri primer dan manufaktur adalah sektor basis. Jadi sektor pertanian di Kota Bitung dapat digolongkan sebagai sektor basis, walaupun LQ sektor pertanian lebih kecil satu. Tabel 5 menunjukkan bahwa LQ sektor pertanian meningkat terus sejak tahun 2010. Peningkatan tersebut konsisten dengan ditetapkannya sub sektor perikanan tangkap sebagai sektor unggulan dan semakin memperkuat pernyataan sektor pertanian sebagai sektor basis di Kota Biutng.

Tabel 5. Nilai LQ Masing-Masing Sektor dari Tahun 2010 Sampai 2019

\begin{tabular}{lccc}
\hline \multicolumn{1}{c}{ LAPANGAN USAHA } & $\mathbf{2 0 1 0}$ & $\mathbf{2 0 1 5}$ & $\mathbf{2 0 1 9}$ \\
\hline A. PERTANIAN, KEHUTANAN \& PERIKANAN & 0.75 & 0.79 & 0.85 \\
B. PERTAMBANGAN DAN PENGGALIAN & 0.11 & 0.10 & 0.10 \\
C. INDUSTRI PENGOLAHAN & 3.66 & 3.55 & 3.48 \\
D. PENGADAAN LISTRIK DAN GAS & 0.86 & 0.96 & 0.93 \\
E. PENGADAAN AIR, PENGOLAHAN SAMPAH, LIMBAH DAN DAUR & 1.55 & 1.53 & 1.49 \\
ULANG & 0.74 & 0.81 & 0.83 \\
F. KONSTRUKSI & 0.66 & 0.69 & 0.75 \\
G. PERDAGANGAN BSAR DAN ECERAN; REPARASI MOBIL DAN & 1.35 & 1.50 & 1.59 \\
SEPEDA MOTOR & 0.40 & 0.37 & 0.39 \\
H. TRANSPORTASI DAN PERGUDANGAN & 0.46 & 0.44 & 0.45 \\
I. PENYEDIAAN AKOMODASI DAN MAKAN MINUM & 0.83 & 0.80 & 0.89 \\
J. INFORMASI DAN KOMUNIKASI & 0.68 & 0.64 & 0.66 \\
K. JASA KEUANGAAN DAN ASURANSI & 0.29 & 0.27 & 0.27 \\
L. REAL ESTATE & 0.26 & 0.27 & 0.28 \\
M,N JASA PERUSAHAAN & & &
\end{tabular}

Agrisosioekonomi:Jurnal Transdisiplin Pertanian (Budidaya Tanaman, Perkebunan, Kehutanan, Peternakan, Perikanan), Sosial Ekonomi dan Teknologi Pangan serta Teknologi Pertanian 


\section{SOSIAL WAJIB}

P. JASA PENDIDIKAN

Q. JASA KESEHATAN DAN KEGIATAN SOSIAL

0.24

0.57

R,S,T,U JASA LAINNYA

0.42

0.30

0.43

0.30

0.57

Sumber: Diolah dari data sekunder 2020

\section{KESIMPULAN DAN SARAN}

\section{Kesimpulan}

Berdasarkan hasil penelitian, dapat ditarik kesimpulan bahwa sektor pertanian memiliki peran yang sangat penting terhadap perekonomian Kota Bitung. Kontribusi sektor pertanian menempati urutan kedua sesudah industri pengolahan, PDRB sektor pertanian terus mengalami pertumbuhan. Nilai LQ sektor pertanian walaupun lebih kecil satu tetapi terus meningkat, seiring dengan ditetapkannya sub sektor perikanan tangkap sebagai sektor unggulan, penyedia konsumsi ikan di Sulawesi Utara, dan sebagai penyedia bahan baku utama industry pengolahan ikan di Kota Bitung.

\section{Saran}

Sektor pertanian memiliki peranan penting bagi perekonomian Kota Bitung, maka disarankan agar pemerintah Pemerintah Kota Bitung terus meningkatkan dan mengembangkan sektor pertanian, khususnya perikanan tangkap sehingga kesejahteraan masyarakat, khususnya nelayan semakin meningkat.

\section{DAFTAR PUSTAKA}

Antara, M. 2009. Pertanian, Bangkit atau Bangkrut. Arti Foundation. Denpasar

Arsyad, Lincolin. 1999. Pengantar Perencanaan dan Pembangunan Ekonomi Daerah. BPFE. Yogyakarta

--------------, 2010 Ekonomi Pembangunan, Yogyakarta UPP STIM YKPN.

Badan Pusat Statistik, Kota Bitung Dalam Angka 2020. BPS Kota Bitung: https://bitungkota.bps.go.id/diakses.23april2020 Daniel, Moehar. 2002. Pengantar Ekonomi Pertanian. Bumi Aksara. Jakarta.

Glasson J.,1974. An Introduction to Regional Planning (terjemahan Sihotang P.), Lembaga Penerbit Fakultas Ekonomi Universitas Ekonomi, Jakarta.
Isserman, Andrew. M. 1977. The Location Quotient Approach for Estimating Regional Economic Impacts: AIP Journal.

Jhingan, M. L. 2005. Ekonomi Pembangunan dan Perencanaan. PT. Raja Grafindo Persada.

Miller. M.1991. Location Quotient Basic Tool for Economic Development Analysis. Economic Development Review, 9(2);65.

Permana, Anggit Y. 2012. Analisis Pengaruh PDRB, Pengangguran, Pendidikan dan Kesehatan Terhadap Kemiskinan di Jawa Tengah tahun 2004-2009. Skripsi. FEB UNDIP. Semarang.

Pratomo, Satriyo. 2010. Analisis Peran Sektor Pertanian Sebagai Sektor Unggulan di Kabupaten Boyolali. Skripsi. FE UNS. Surakarta.

Rangkuti, F. 2006. Analisis Location Quotient Teknik Membedah Kasus Bisnis. PT. Gramedia Pustaka Utama: Jakarta.

Resthiningrum, Raras. 2011. Keragaan dan Peran Sektor Pertanian Dalam Perekonomian Wilayah di Kabupaten Blora. Skripsi. Fakultas Pertanian UNS. Surakarta.

Ron Hood. 1998. Economic Analysis: A Location Quotient. Primer. Principal Sun Region Associates, Inc.

Somba, Henry. 2019. Telegra news. Bitung https://telegrafnews.co/2019/09/gepita-sebutsektor-pertanian-kota-bitung-punya-potensibesar.html//dikases 23 APRIL 2020.

Sudrajat, Edi. 2017. Analisis Location Quotient (LQ) Tentang Potensi Pengembangan Sapi rakyat di Kabupaten Gowa. Skripsi. Jurusan Ilmu Peternakan Fakultas Sains dan Teknologi Universitas Islam Negeri Alauddin Makasar.

Sukirno, S. 1996. Pengantar Teori Makroekonomi. Raja Grafindo Persada. Jakarta.

Sukirno, S. 2005. Ekonomi Pembangunan. Fakultas Ekonomi. Universitas Indonesia. Jakarta.

Syafrizal. 2008. Ekonomi Regional: Teori dan Aplikasi. Badouse Media. Padang Todaro, M. 2000. Pembangunan Ekonomi Dunia Ketiga. Erlangga. Jakarta https://id.m.wikipedia.org/wiki/Kota_Bitung/dia kses 23 april 2020

https://candygloria.wordpress.com/2011/04/06/pemban gunan-ekonomi-daerah/diakses 22 april 2020. 